\title{
L1 in the IRF cycle: a case study of Chinese EFL classrooms
}

Jingya LiD

Correspondence: jingyali2013@163.com

School of Education, University of New South Wales, Flat 21, 255-271 Anzac Parade, Kingsford, Sydney, NSW 2032, Australia

\begin{abstract}
The Initiation-Response-Feedback (IRF) cycle (teachers' initiation, students' response and teachers' feedback) has been a key focus in studies of second language classroom interaction and participation. This paper aims to examine the influence of the first language (L1) in the Initiation-Response-Feedback (IRF) cycle commonly appearing in teacher-fronted classroom interaction. Previous studies have come to different conclusions about the role and value of L1 in the IRF cycle. The direct method underpinning the avoidance of L1 has been adopted since 1880s. The use of L1 is not discussed in language pedagogy in the last decade or two and some researchers consider the occurrence of the $\mathrm{L} 1$ as a problem. On the other hand, recent studies show that $\mathrm{L} 1$ can be used as a mediating language to create effective learning context for second language acquisition. However, these arguments are discussed either from a theoretical position or in a general classroom context and pay less attention to what is happening in micro interactions.

This paper addresses the effect of using L1 in English as a foreign language classroom through an examination of the micro IRF cycle in English language classrooms in China. The data was collected through video recordings in a senior high school in China and analysed through conversation analysis. The analysis suggests that L1 used in the IRF cycle can function as a key to open up dialogue and bring more target language into the conversation. I argue that L1 in the IRF cycle can be used as a mediating tool and promote acquisition of the target language. This study will provide new insights into the role of $L 1$ in teaching and learning interactions.
\end{abstract}

Keywords: The initiation-response-feedback cycle, EFL classrooms, The first language (L1)

\section{Introduction}

One area in classroom discourse that has been investigated for decades is the Initiation-Response-Feedback (IRF) cycle commonly applied in teacher-fronted classroom interactions (Mercer and Dawes 2014; Poole 1990). Whether the IRF cycle is used effectively may influence learning opportunities in classroom discourse. IRF cycle consists of three moves: an initiation refers to a teacher's directive or informative instruction to be publicly understood; a response refers to students' reaction (focusing on verbal reaction essentially) to show their understanding of the teacher's instruction; and a feedback provided by the teacher to display attitude, comments or evaluation in the light of pedagogical goals (Hellermann 2003; Sinclair and Coulthard 1975; Wells 1993). In broad sense, the definition of the IRF cycle includes not only the basic IRF

(c) The Author(s). 2018 Open Access This article is distributed under the terms of the Creative Commons Attribution 4.0 International License (http://creativecommons.org/licenses/by/4.0/), which permits unrestricted use, distribution, and reproduction in any medium, provided you give appropriate credit to the original author(s) and the source, provide a link to the Creative Commons license, and indicate if changes were made. 
sequence, but also the developed moves on the basis of the Initiation (I), Response (R), and Feedback (F) moves.

The IRF cycle has been investigated in terms of its moves, sequences, and its functions in classroom interactions and few studies pay attention to the bilingual context where the IRF cycle occurs. This is probably because of the assumption that Howatt (1984) points out emphasizing the monolingual context for second or foreign language acquisition. Language is considered as separate systems in which the first language (L1) and the second language (L2) are used to refer to different language systems. It seems axiomatic that the target language should be learned through the target language only (Cummins 2008). The more exposure of the target language, the more learners 'make progress' in the target language (Philip 2016, p. 514).

However, considering the language teaching practice especially in a non-native speaking environment, it is found difficult to create a monolingual context and avoid using learners' L1. In non-English speaking countries, the bilingual context seems to be 'unavoidable' in classroom discourse especially for students at lower language proficiency level (Philip 2016, p. 514). According to Hall and Cook (2013)'s study on English language teaching in 111 countries, almost $45 \%$ of participants reports that they make their own-decisions on the choice of language in the classroom. It seems that there is a conflict between the ideal teaching and the teaching practice. However, the conflict will not exist if L1 is considered as a positive factor in language classrooms. 'There is a very clear consensus that some own-language use can support the learning of a new language, Philip (2016, p. 523) argues. This argument is supported by Laviosa (2014) who underpins the central role of L1 in developing translation skills and cognitive thinking.

Given the flexible and dynamic feature of classroom interactions, the function of L1 cannot be generalized for one-fits-all model. As Philip (2016) argues, bilingual resources are co-constructed with a wide range of variables. For instance, students' language proficiency level may affect the amount of students' L1(s) used in classroom interactions (Hall and Cook 2013). It is reported by studies such as Littlewood and $\mathrm{Yu}$ (2011), Macaro (1997) and Mitchell (1988) that students prefer to use L1 because of their poor language proficiency and lacking of confidence. The size of the class (Littlewood and Yu 2011), different types of classroom activities and pedagogical goals also play a role in shaping the way L1 is applied and its influence in classroom interactions (Philip 2016). The social and cultural factors embedded in code-switching such as the relationship between learners and the teacher in classroom contexts should also be considered (Auer 1998). Auer (1998) argues that code-switching not only relates to linguistic or grammatical changes of codes but also is influenced by participants' identity, teaching and learning experience as well as pedagogical purposes in specific classroom contexts. Therefore the function of L1 is more likely to be context-related and contingent rather than fixed and predetermined. The functions of L1 in specific classroom contexts are revisited in the literature review.

In this respect, this paper aims to explore L1 use in classroom interactions and unfolds how language learning opportunities can be affected by L1 use. In order to choose a bilingual classroom context, this study selects English as a foreign language classroom (EFL) in a senior high school in China as the research context. Within Chinese EFL classrooms, the Initiation-Response-Feedback (IRF) cycle is commonly applied in 
classroom interactions. This study focuses on the IRF cycle in Chinese EFL classrooms in particular and takes account of contextural factors at moment.

\section{Literature review}

\section{The function of $\mathrm{L} 1$ in classrooms}

The function of L1 in classrooms has been examined and discussed by a number of researchers (Cummins 2008; Kim and Elder 2005; Littlewood and Yu 2011; Macaro 2005; Philip 2016). They summarize the function of L1 into different categories. Combining those categories the functions of L1 are outlined in terms of Philip (2016, p. 516)'s 'classificatory system' namely 'medium-oriented' or 'core' functions and 'framework' and 'social' functions as shown in Fig. 1. In former aspect, L1 use focuses on language acquisition such as explaining grammar and seeking equivalent structure of the target language. The later aspect emphasizes L1 in classroom management such as getting touch with students and maintaining classroom rapport. Apart from functions summarized by Philip (2016), L1 is also reported to save time, speed up the pace of teaching and maintain the naturalness of the language such as setting up background (Cook 2001; Harbord 1992; Macaro 2005).

(Adapted according to Cook (2001); Cummins (2008); Harbord (1992); Littlewood and Yu (2011); Macaro (2005); Philip (2016))

Since the teacher may apply L1 for different functions at the same time, overlapping of categories can be found in two aspects. These functions can be positive or negative in the light of specific classroom discourse. Researchers such as Cohen (2011), Littlewood and Yu (2011) prefer a monolingual context for language learning and consider L1 as a 'crutch' that prevents students from language independent learning. However, some researchers (Cummins 1979; Cummins 2008; Hall and Cook 2012, 2013; Philip 2016; Üstünel and Seedhouse 2005) emphasize the positive aspect of L1 to support foreign language learning.

On the one hand, some studies have shown that L1 is considered as minimal influence on EFL/ESL acquisition in schools in English-speaking countries such as in the United States and Canada (Cummins 2005). The monolingual context and Language separation pedagogy is underpinned in language school classrooms (Liu 2007; Wei and Wu 2009). A second or foreign language is believed to be better acquired through the use of the language in a monolingual context (Heller 2006). In this respect, the pedagogical goals emphasize the

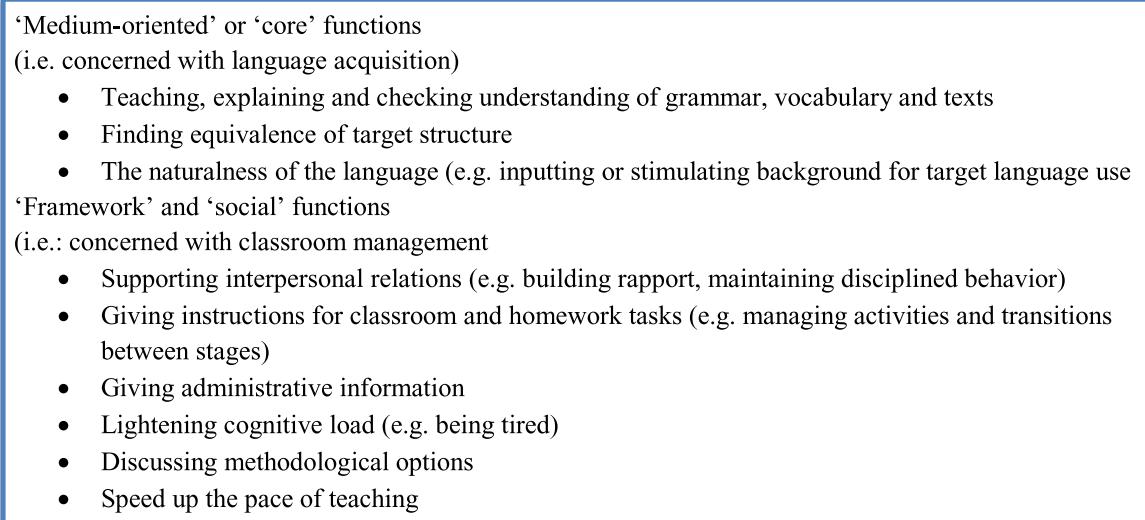

Fig. 1 Function of L1 in classroom 
maximal exposure of the target language in language classrooms and minimize the appearance of L1 (Blackledge and Creese 2010). The limitations of L1 are summarized into two aspects: too much reliance on L1 and L1's habits interference.

One limited aspect concerns with the cause of students' over dependence on L1 and less time and opportunities left to expose the target language. Teachers are afraid of not giving enough time to practice L2 if L1 is used consciously or unconsciously in the classroom (Philip 2016). For example, Stern et al. (1992) argues that the cross-lingual translation from L2 to L1 or from L1 to L2 discourages students to use L2 to understand L2 and relies too much on L1. He insists that the translation from L1 to L2 can 'result in an uneconomical use of learning time' (Stern et al. 1992, p. 296). Had intralingual responses been encouraged, 'a more fruitful exposure' of the target language would have promoted (Stern et al. 1992, p. 296). Macdonald (1994) believes that it is unnecessary to use L1 as explanations in that it slows down the learning process. Teachers may switch to L1 unconsciously because of the tiredness and the 'natural communicative instincts'(Littlewood and Yu 2011, p. 73). They believe that the more L1 occurs in language classrooms the less L2 occurs in the limited classroom teaching and learning time.

Another limitation of L1 underpins L1 interference resulting in limiting L2 acquisition. Such interference occurs because learners' L2 habits can be transferred from their habits of L1 (Butler and Hakuta 2004). Newson (1998) advocates that translations between L1 and L2 mislead learners to look for equivalent symbols between two languages which seem impossible. It is supported by the theory of audiolingualism that emphasizes the monolingual context of L2 to avoid being interfered by L1 (Baker 1996).

However, these limitations are criticized by studies focusing on bilingual classrooms. The importance of L1 in language classrooms regains attention in the literature. Researchers begin to look back the role of L1 in classrooms and factors behind its existence. Recent studies found that L1 has positive effects on language acquisition and can create learning opportunities in classroom contexts. The theory is developed from Cummins' developmental interdependent hypothesis Cummins (1979) emphasizing the importance of pre-existing knowledge in learning process. A number of empirical studies are designed to examine the role of L1 in educational environment based on developmental interdependent hypothesis.

Cummins' developmental interdependence hypothesis emphasizes the cognitive advantages of using L1 to acquire new knowledge (Cummins 1979). It is argued that the pre-existing knowledge which is often coded in learners' first language is 'a foundation for learning' (Cummins 2008, p. 67). The theory is supported by a study conducted by Verhoeven (1991) who found that L1 functions positively not only in the teacher's instructions but also literacy in both L1 and L2. In his study he examines the programs with L1 literacy promoted in primary schools and found that there is an interdependent development between L1 and L2. The study reports that 'literacy skills being developed in one language strongly predict corresponding skills in another language acquired later in time' (Verhoeven 1991, p. 72). This argument is echoed by Baker (1996) who highlights the word 'transfer' of skills and learning strategies across languages (p. 324).

One significant concept developed from developmental interdependence hypothesis is the cross-lingual mediation. In classroom context, cross-lingual mediation is implemented 
through social structure and linguistic structure. In terms of social structure, L1 is considered as the facilitation of positive communication and learning environment as shown in Fig. 1. L1 can be used to maintain discipline, keep in touch with students and foster classroom rapport (Macaro 2005; Philip 2016). A close examination of teachers' view and students' perspectives in Pablo et al. (2011)'s study shows that L1 is used to establish rapport and create positive learning environment. Through L1 embarrassing moments can be reduced so as to encourage students' participation in classroom interactions (Philip 2016). The cross-lingual mediation also functions positively on learning linguistic forms. Pablo et al. (2011, p. 122) consider L1 as a 'learning aid' in understanding vocabulary and grammar. Cook (2002) reviews teacher's opinions about L1 use from a number of empirical studies and found that L1 is commonly used as a resource to convey meanings and explain grammar.. It is consistent with studies from Franklin (1990) and Macaro (1997) showing that using L1 to explain grammar is more efficient than L2 in that student find it difficult to gain grammatical information through L2.

\section{The role of L1 in the IRF cycle}

Although L1 is gained more concern in the acquisition of L2, there are few indepth case studies focusing on the function of L1 in the specific IRF cycle in classroom interactions. Initially, L1 is discussed from a theoretical perspective by the researchers such as Cook (2001), Littlewood and Yu (2011), Hall and Cook (2012), and Philip (2016). For instance, Cook (2001) re-examines the previous studies and argues that in most cases of foreign language classrooms it is impossible to avoid using L1. Hall and Cook (2012)'s study discusses the function of L1 by relating them to theoretical frameworks. Philip (2016) summarizes the teaching practices and attitudes of L1 in previous study and evokes the crucial role of L1 in foreign language classrooms. However, their conclusions are limited to theoretical position and pay less attention to empirical classroom practices which is dynamic and flexible from moment to moment.

With the development of teaching practices, some studies (Hall and Cook 2013; Pablo et al. 2011) begin to explore the application of L1 from the teacher's views and students' perspectives. For example, Hall and Cook (2013) investigate the teacher's perceptions of L1 used in English language classrooms through postal questionnaires. They found a mismatch between the theory and practice of L1 application, which requires more empirical studies on specific classroom teaching practices (Hall and Cook 2013). Pablo et al. (2011)'s study focuses on understanding participants' perceptions of L1 and ignores the importance of ongoing classroom interactions. Those studies are grounded on general classroom interactions and pay less attention to a deep analysis of specific interactional patterns where pedagogical goals and language code may change from moment to moment.

By reviewing the function of L1 investigated in the literature, there is a need to explore the role of L1 in depth in different classroom contexts. As Polio and Duff (1994) argues, it is difficult to generalize the function of L1 across classes and they suggest an in-depth case study on teacher-student interaction. The social and cultural factors embedded in language also play an important role in shaping the way of learning and cognitive thinking (Butler and Hakuta 2004). This study investigates the function of L1 
from both micro and macro perspectives by examining the use of L1 in the IRF cycle in Chinese EFL classrooms. Specific research questions are listed below:

1) How does L1 occur in the IRF cycle in Chinese EFL classrooms?

2) How to use L1 to promote language learning opportunity in different IRF cycles?

3) What are the hinder factors that can affect the application of L1 in the IRF cycle from a sociocultural perspective?

\section{Methods}

The sample

The research is conducted in English as a second or foreign language classroom in a senior high school in China. Students are in year-12, whose English language proficiency is intermediate. All students are from China and share similar social and cultural background. Students speak Chinese Mandarin as their first language and English as their foreign language. Their EFL course is taught by English non-native speaker who speak Chinese Mandarin as his/her first language and English as his/her foreign language. In this case, the teacher and students share the same L1 which is Chinese Mandarin and similar cultural background.

There are four classrooms observed including four different classes and two different teachers. Each class has approximately 60 to 70 students. The type of lesson includes grammar lesson, reading skills, and vocabulary. In terms of curriculum, English is taught in both students' L1 and English. The textbooks and teaching materials are also presented bilingually. However, students are only assessed through exams in English.

\section{Research instrument}

This study is a qualitative case study. The data is obtained through classroom observation and video recordings. There are two cameras and two audio recordings placed in the classroom. Voices from teachers and students, gestures, participants' appearance are captured and transcribed according to Hutchby and Wooffitt (2008)'s transcription system ${ }^{1}$ (see also Jefferson (2004)). There is no researcher's intervention during the whole observation. The researcher sits at the corner of the classroom.

The data is analyzed through ethonomethodological conversations analysis (ECA) put forward by Seedhouse (2007). ECA is developed from traditional conversation analysis (CA) emphasizing both structure and order of interactive talk (Seedhouse 2004) as well as on the social and contextual factors. Regarding the bilingual context where the IRF cycle occurs, this study applies ECA to build a link between micro interactional moves and the broader bilingual classroom discourse. The analysis follows 'bottom-up and data driven' approach (Seedhouse 2004, p. 15). There are no pre-determined structures, terms or even theoretical assumptions unless data show a clue of relevance. Both sequences of conversation and the broader bilingual contexts are highlighted to examine how L1 is structured and shifted in the IRF cycle. ECA provides a detailed analysis of the language embedded contexts in the IRF cycle and allows exploring the function of L1 in depth. 
Last but not least, the data is also analyzed on the basis of sociocultural perspective put forward by (Vygotsky and Cole 1978). According to sociocultural perspective, language is acquired first through social activities influenced by social and cultural factors brought by participants. In this respect, participants' bilingual resources such as their L1 play an important role in shaping the structure of the IRF cycle and language learning opportunities. This study examines the function of L1 in the IRF cycle and also uses the sociocultural perspective to explain the reasons beyond the phenomenon.

\section{Results}

\section{Research question 1: How does L1 occur in the IRF cycle in Chinese EFL classrooms?}

The transcripts present a bilingual classroom context where both English as a target language and Chinese as participants' first language occur alternatively in IRF cycles. In some IRF cycles, target language is used more frequently than participants' first language (L1); while in some IRF cycles, participants' L1 dominates the whole exchange. The code switching in the IRF cycles is determined by specific pedagogical goals and the dynamic feature of classroom interactions. Consistent with the first research questions, the following paragraphs explore how L1 is applied in the IRF cycle in the four Chinese EFL classrooms.

\section{L1 as a classroom script}

One classroom script emerges from the transcripts is that students are allowed to use their L1 to participate in the IRF cycle. Excerpt 1 below provides an example that L1 is officially permitted by the teacher in the IRF cycle.

\section{Excerpt 1 (from Ms. Ding's Class A): the use of first language as script}

\begin{tabular}{|c|c|c|c|}
\hline \multicolumn{3}{|c|}{ Transcripts } & \multirow{2}{*}{$\begin{array}{l}\text { Discourse moves } \\
\mathrm{TI}^{2}\end{array}$} \\
\hline 1. & Teacher: & $\begin{array}{l}\text { If you have the right answer, you can stand up and give me the } \\
\text { answer. 谁有了答案就可以站起来说 [If who has the answer, just stand up/ }{ }^{1} \text {. } \\
\text { 讲这五个地点分别是哪里 [Tell us what are the five places], 可以说一个, 两个, 三个都行 [you } \\
\text { can say one, two or three] }\end{array}$ & \\
\hline 2. & Students: & (10) ((Silence)) & SR \\
\hline 3. & Teacher: & You also can say Chinese if you can't speak English & TF \\
\hline 4. & Students: & (5) ((Silence)) & SR \\
\hline 5. & Teacher: & $\begin{array}{l}\text { Now class, be quick. } \\
\text { Five places, which are they? }\end{array}$ & $\begin{array}{l}\text { TF } \\
\text { TI }\end{array}$ \\
\hline 6. & Wu: & (7) 第一个是圣保罗大教堂 [The first one is St Paul's Cathedral] & S1R \\
\hline 7. & Teacher: & $\begin{array}{l}\text { St Paul's Cathedral, yeah. } \\
\text { Next one? }\end{array}$ & $\begin{array}{l}\text { TF } \\
\text { TI }\end{array}$ \\
\hline 8. & Wu: & 威斯钽斯特教堂 [Westminster Abbey] & S1R \\
\hline 9. & Teacher: & $\begin{array}{l}\text { Westminster Abbey. } \\
\text { The third one? }\end{array}$ & $\begin{array}{l}\text { TF } \\
\text { TI }\end{array}$ \\
\hline 10. & Wu: & Big Ben & S1R \\
\hline 11. & Teacher: & $\begin{array}{l}\text { Big Ben, yeah. } \\
\text { The fourth one? }\end{array}$ & $\begin{array}{l}\text { TF } \\
\text { TI }\end{array}$ \\
\hline 12. & Wu: & 白金汉宫 [Buckingham Palace] & S1R \\
\hline 13. & Teacher: & $\begin{array}{l}\text { Yeah, Buckingham Palace. } \\
\text { Now class, did you find the four places? }\end{array}$ & TF \\
\hline
\end{tabular}

Excerpt 1 shows a task-based activity where Ms. Ding is eliciting answers from students. The pedagogical focus is on meaning rather than form of the language. The conversation begins with the L2 and then is changed to the L1 to simplify the task (line 1). Despite of this, students still keep silent for $10 \mathrm{~s}$ (line 2), which indicates a problem in answering this question. In order to facilitate students' contributions, Ms. Ding allows students to use L1 (line 3). Successfully, Wu volunteers to participate with four turns (line $6,8,10,12$ ). The teacher's permission to 
use L1 can be considered as a turning point after which opens up the conversation.

According to the transcripts, L1 is used in the IRF cycle as a classroom script to achieve a certain teaching purpose. Students seem to get used to the bilingual environment and be able to switch from one language to another. As shown in excerpt 1, except the first initiation (line 1), Ms. Ding's all turns are in L2, while most of Wu's responses are in L1. It appears that Wu feels comfortable to access information through L2 and output the knowledge in L1. It is also interesting to notice that $\mathrm{Wu}$ also tries to use $\mathrm{L} 2$ as much as possible as shown in line 10. Excerpt 1 reveals that L1 as a script can encourage students' participation and facilitate a communicative interaction.

\section{Prompting responses through L1}

The data reveals a cross-lingual mediation between L1 and L2 in the IRF cycle when the teacher is prompting students' responses based on a form-focused activity. As observed from the transcripts, L1 can be used in prompts to elicit students' responses, aiming to highlight a pedagogical focus. Under such circumstance, L1 plays a role of metalanguage to elicit students' understanding of L2. As shown in excerpt 2, prompts in Ms. Ding's turns occur three times (line 3, 5, 7) in the IRF cycle.

\section{Excerpt 2 (from Ms. Ding class B): Prompting students' responses}

\begin{tabular}{|c|c|c|c|}
\hline \multicolumn{3}{|c|}{ Transcribed interaction data } & \multirow{2}{*}{$\begin{array}{l}\text { Discourse moves } \\
\text { TI }\end{array}$} \\
\hline 1. & Teacher: & Now let's come to this one, 'at the sight of'. 'At the sight of the policeman the thief ran away' & \\
\hline 2. & Students: & 在某人眼中 [‘the sight of somebody’] ((One student is responding)) & SR \\
\hline 3. & Teacher: & 'At the sight of' means on seeing the policeman, the thief ran away. & TF \\
\hline 4. & Students: & (1) 某人 [The sight] ((A few students are repeating)) & SR \\
\hline 5. & Teacher: & (2) 怎么解释 [How to explain]? 一看见警察小偷呢 ['At the sight of the policeman, the thief']”: & $\mathrm{TF}$ \\
\hline 6. & Students: & 跑了 [Ran away] ((Few students are whispering in a low voice)) & SR \\
\hline 7. & Teacher: & 就跑了[Ran away immediately]. 所以 [So] 'at the sight of'一看见什么什么 [means '.... seeing'] & TF \\
\hline 8. & Students: & 就 [On] ((2 students are responding)) & SR \\
\hline 9. & Teacher: & 就 [On], 一有见什么什么就 ['at the sight of']. & $\mathrm{TF}$ \\
\hline
\end{tabular}

In this interaction, Ms. Ding is giving feedback on a task-based activity. She starts the conversation in L2 using attention language including signal of boundaries and citations from the task sheet (line 1). In the next turn, only one student responds to the teacher's initiation (line 2). In order to elicit more students' turns, Ms. Ding provides a prompt using L2 to explain the linguistic meanings. At this time, more students are participating but not in an effective way in that student participants are repeating the student's previous answer (line 4). In the next feedback move, Ms. Ding switches the language into L1 beginning with a reinitiation 'how to translate' (line 5), followed with a linguistic clue. Although few students are whispering in a low voice, students manage to provide different ideas (line 18), which indicates an occurrence of their cognitive thinking. L1 in this case functions more effectively than L2 in line 1, 3. Considering the positive effect of L1, Ms. Ding uses a slight modification and initiates another prompt in L1 (line 7). Since students are more sensible with L1, two students successfully recognize the meaning that the teacher intends to underpin (line 8).

The data shows that L1 used in the teacher's prompt can facilitate students' selfrepair where language learning opportunities are embedded. Students' self-repairs are 
observed in excerpt 2 are elicited successfully through Ms. Ding's use of L1 (line 5, 7). The linguistic focus is recognized by students (line 8) after Ms. Ding's prompts in L1 (line 7) when L2 fails to do it at first time (line 1, 3). In other words, L1 can provide a familiar context for students to explore the forms and meanings of L2. Ms. Ding's help in L1 aims at ensuring students' understanding of her language. As presented in excerpt 2 (line 6,8), students' self-repair cannot be elicited if they cannot understand Ms. Ding's prompt through L2 only.

\section{Giving instruction through L1}

It is observed from the transcripts that the teacher's instructions in L1 can help students in concentrating on the meaning of L2. Although giving instructions through L1 reduces opportunities of practicing L2, it simplifies the task by verifying communicative meaning in the IRF cycle. The following excerpt shows an example of giving instructions in Ms. Ding's class A. Instead of struggling to understand what the teacher is saying, students in excerpt 3 can spend more time on pedagogical goals.

\section{Excerpt 3(from Ms. Ding's class A): Giving instructions through L1}

\begin{tabular}{|c|c|c|c|}
\hline \multicolumn{3}{|c|}{ Transcripts } & \multirow{2}{*}{$\begin{array}{l}\text { Discourse moves } \\
\text { TI }\end{array}$} \\
\hline 1. & Teacher: & Number 15-number 18. 后四个谁来说 /The last four, who wants to have a try]? & \\
\hline 2. & Zhao: & (3) 后四个是 [The last four arel 'develop communism' & S1R \\
\hline 3. & Teacher: & 'Develop communism' & $\mathrm{TF}$ \\
\hline 4. & Zhao: & 'Displayed' 展出 [means 'display'] & S1R \\
\hline 5. & Teacher: & $\begin{array}{l}\text { 恩 [Yeah] } \\
\text { 展出是什么? [How to say 'display'] }\end{array}$ & $\begin{array}{l}\text { TF } \\
\text { TI }\end{array}$ \\
\hline 6. & Zhao: & 'Displayed' & S1R \\
\hline 7. & Teacher: & 'Explain'? & $\mathrm{TF}$ \\
\hline 8. & Zhao: & 'Displayed' & S1R \\
\hline 9. & Teacher: & 'Display'这个词是吗 [this word, right]? & TF \\
\hline 10. & Zhao: & 恩 [Yeah] & S1R \\
\hline 11. & Teacher: & $\begin{array}{l}\text { 除了'display'这个单词之外[Except the word 'display'], 大家看一下是不是还有一个词组 [let's } \\
\text { see if there is a phrase], 往下走 [the following part], 什么 /What is it]? }\end{array}$ & TF \\
\hline 12. & Zhao: & 'On show' & S1R \\
\hline 13. & Teacher: & $\begin{array}{l}\text { 'On show', yes. } \\
\text { Number } 17 \text { ? }\end{array}$ & $\begin{array}{l}\text { TF } \\
\text { TI }\end{array}$ \\
\hline 14. & Zhao: & 'Pride of' & S1R \\
\hline 15. & Teacher: & 'Be proud of' & TF \\
\hline
\end{tabular}

Excerpt 3 is a teacher-fronted interaction. The teacher is giving feedback on a vocabulary-based exercise. To start the conversation, Ms. Ding uses L2 as attention language, followed with L1 for explanations. In this instruction Ms. Ding intends to use both L1 and L2 to elicit L2. In terms of Zhao's answers, L2 is identified in six out of seven turns, which indicates a successful elicitation. It is also interesting to notice that when L1 used in Ms. Ding's turns are increasing (line 5, 11), L1 in Zhao's turns are fading away (line 6, 12). It suggests that when the teacher puts more L1 in instructions to assist students' understanding, students can concentrate more on L2. Specifically, Zhao's answer is not accepted by Ms. Ding in line 11. In order to guide Zhao in finding out a certain form, Ms. Ding uses L1 rather than L2 which may not be accessible for students in her instructions to simplify the task. The linguistic form is realized successfully by Zhao in line 13, which suggests an effective instruction.

A key feature revealed from excerpt 3 is that a well-defined amount of L1 in the teacher's instructions can remove students' uncertainty and facilitate acquisition of L2. In student Zhao's turns, there is no hesitation or misunderstanding of Ms. 
Ding's instructions. All content of the conversation focuses on the vocabularybased exercise in L2. Zhao's responses, except attention language (line 2, 4) and confirming language (line 10) used in L1 are all in L2 with a particular focus on form of the target language. It can be seen that giving instructions in L1 can provide a short-cut to convey meanings so that acquisition of L2 can be highlighted.

\section{Discussion}

\section{Research question 2: How to use L1 to promote language learning opportunity in different IRF cycles?}

Although L1 can encourage students' participation and facilitate complex contributions in the IRF cycle, it should be applied properly to avoid 'natural communicative instincts' of using L1 unconsciously (Littlewood and Yu 2011, p. 73). First, in meaning-focused IRF cycles, L1 can be used to in students' responses to promote a more dialogic interaction. Rather than modelling the use of language in form-focused IRF cycle, fluency and communicative purposes are emphasized in meaning-focused IRF cycle where L1 may offer appropriate expressions for communication (Kim and Elder 2005). Waring (2009, p. 817) advocates that the restricted IRF cycle is 'almost impervious to restructuring'. However, it is revealed from the transcripts that L1 can provide an opportunity to facilitate students' extended turns and break the restricted patterns. It echoes Cook (2001)'s finding that L1 can be used to keep in touch with students and maintain classroom rapport. A relaxing atmosphere can be established through L1 to encourage students' participation (Pablo et al. 2011). As shown in excerpt 1, students pay more attention to the meaning that language conveys and use L1 as a tool to interpret L2. Compared with the silence turns at the beginning of the conversation, an increasing number of students are participating after L1 is permitted. The results also support Philip (2016)'s argument that L1 has the potential to reduce awkward moment and encourage participation.

Second, L1 can be used to scaffold learning in form-focused IRF cycles. The transcripts show that L1 can facilitate the development of L2 in the form-focused IRF cycle. It echoes Pablo et al. (2011, p. 122)'s argument that L1 can serve as a 'learning aid' in understanding vocabulary and grammar. Instead of struggling to understand L2, students seem to be easier to access L2 through metalinguistic clues in L1. The results respects Cummins' developmental interdependent hypothesis Cummins (1979) emphasizing the importance of pre-existing knowledge in learning process. The familiar L1 resources can help to stimulate students' prior knowledge and push their knowledge boundaries through the input of L2 (Gibbons 2014). As presented in excerpt 2, students are guided by the teacher in exploring the meaning of the target language. Compared with the teacher's initial turns in L2, the teacher's prompts in L1 in following turns seem more accessible for students. The development of students' understanding is identified, which may not occur without the teacher's scaffolding in L1.

Third, the teacher can use L1 in his/her instructions to elicit L2 in students' responses. L1 in this case serves as a mediating tool to elicit complex ideas in L2. It takes the view of sociocultural perspective that language is developed through social interactions (Swain and Lapkin 2000). L1 used in classroom interactions can 
facilitate internalization of the knowledge or metal development (Antón and DiCamilla 1998). It can be seen in excerpt 3 that giving instructions through L1 can simplify the tasks and encourage students to concentrate on L2. L1 in students' responses are reducing and L2 in students' responses are increasing. The more L1 used in the teacher's turns, the less L1 occurs in students' turns. The phenomenon indicates that students pay more attention to the pedagogical goals in L2 when L1 in the teacher's instructions are highly condensed to elicit complex understanding of L2. Even though L2 only environment can maximize the exposure of L2 as supported by researchers such as Halliwell and Jones (1991), Macaro (1997), Polio and Duff (1994) and Scrivener (1994), it may consume more time and space to achieve a mutual understanding among the teacher and students. L1, however, can function as a complement to make instructions applicable. Regarding the multicultural contexts where students and the teacher may share different L1 s, Cook (2001, p. 417) argues 'student uses of the L1 do not necessarily mean that the teacher has to know the L1'. A loose control of language code in the IRF cycle and less teacher presence may offer opportunities for peer assistance and encourage students' participation.

Last but not least, it is important to be aware that L1 should be applied with caution on the basis of pedagogical goals and learner needs. The findings from Edstrom (2009)'s study show that there could be no reasons to use L1 but laziness and tiredness. Teachers may switch to L1 unconsciously because of the 'natural communicative instincts'(Littlewood and Yu 2011, p. 73). With this concern, the application of L1 should take account of pedagogical goals in different classroom contexts. As can be seen in excerpt 1 and excerpt 2, L1 in meaningfocused IRF cycle is used more flexible to convey meanings in that different answers in L1 are expected. On the contrary, students are seeking a particular translation in L1 in form-focused IRF cycles. It is evident to see that language learning opportunity occurs when L1 meets specific pedagogical goals. In addition, learner needs and their understanding of classroom instructions in second language classrooms is emphasized by Gibbons (2006). L1 can serve as a tool to facilitate understanding. As Harbord (1992, p. 352) argues, students can easily follow instructions in L1 and focus more on 'productive activities'. The results from excerpt 3 supports their conclusions in that students are found concentrating on pedagogical goals rather than struggling to understand the teacher's instructions when L1 occurs in instructions.

Research question 3: What are the hinder factors that can affect the application of $\mathrm{L} 1$ in the IRF cycle from a sociocultural perspective?

Beyond choice of language code, there are hindered factors that affect how language is used within classroom discourse. Initially, language choice in classroom interactions is influenced by the participants' teaching and learning experience. Participants in Chinese EFL classrooms are influenced by grammar-translation approach in traditional language teaching method since 1980s (Gibbons 2014) where L1 plays an important role in understanding L2. In the classrooms observed, L1 is used as script in the IRF cycle and classroom activities. Students can hear L1 from the teacher and are also allowed to use L1 to participate. Both the teacher and students consider L1 as a mediating tool to learn L2. 
In addition, China is regarded as a large power-distance culture underpinning 'group harmony' and 'face-saving' status-preservation (Stanley 2013, p. 16). With this respect, L1 can create a harmonious atmosphere to encourage students' participation and negotiate meanings. For instance, students are observed more confident and willing to participate when they are allowed to use L1 as shown in excerpt 1. An increasing number of students are participating after the teacher's permission of using L1 (line 3). Meaning is developed and negotiated harmoniously by the teacher and students in a bilingual context. The power relation in the IRF cycle can be balanced through the use of L1 in that both the teacher and students are knowers when communicating in L1.

\section{Conclusion}

To conclude, a detailed analysis of the data reveals that the well-organized L1 in the IRF has the potential to increase language learning opportunities. Considering the dynamic feature of classroom discourse, L1 appears to be context-specific in different IRF cycles rather than one-fits-all model. The occurrence of L1 in students' turns in meaning-focused IRF cycle can break the restricted pattern and elicit students' extended turns. In form-focused IRF cycle, L1 can function as linguistic clues to scaffold students' learning. Students can also benefit from L1 in teacher's instructions so as to keep in touch with the teacher and concentrate on pedagogical goals. Nevertheless, learning opportunities in the IRF cycle change from moment to moment. L1 should be adopted with the concern of pedagogical goals and learner needs. The teacher's decision-making on code switching is not only a planned strategy but also a contingent approach based on students' responses and performance at moment..

Beyond interactional moves, code switching in the IRF cycle is also influenced by learning culture in language classrooms. As discussed above, inheriting from grammar translation approach (Zheng and Davison 2008), L1 is considered as a tool to input background knowledge and vocabulary. Students' familiar context coded in L1 can reduce embarrassing moment and save face valued by Chinese students so as to encourage students' participations. Instead of isolating language acquisition as a pure cognitive process, the transcripts reveal a socioculturally constructed IRF cycle where L1 plays an essential role in shaping the interaction. Rather than ignoring its existence, teachers can take advantage of the overlapping between languages and cultures to promote L2 acquisition.

For the last one decade or two, studies started to re-consider the function of L1 in language classrooms and how it may increase language learning opportunities. This paper provides an in-depth understanding of L1 within the micro IRF cycle and its connection to the broader social and cultural factors in the classroom discourse. However, the conclusion is based on a specific case study in which participants share the same social and cultural background. It would increase the understanding of L1 if future research can shed light on classrooms with multicultural backgrounds. Further, this study focuses on the IRF cycle in particular. The role of L1 in different types of interactions such as group or pair work may provide a deeper understanding of L1.

\section{Endnotes}

${ }^{1}$ See transcription symbols in Appendix 1. 


\section{Appendix 1}

The transcription symbols used here are common to conversation analytic research, and were developed by Gail Jefferson. The following symbols are used in the data.

A more detailed description of these transcription symbols can be found in Atkinson and Heritage (1984: ix-xvi)

Table 1 Transcription symbols

\begin{tabular}{|c|c|}
\hline $\begin{array}{l}\text { Transcription } \\
\text { symbols }\end{array}$ & Descriptions \\
\hline$\overline{(0.5)}$ & The number in brackets indicates a time gap in tenths of a second. \\
\hline (.) & A dot enclosed in a bracket indicates pause in the talk less then two tenths of a second. \\
\hline$\cdot h h$ & A dot before an ' $h$ ' indicates speaker in-breath. The more ' $h$ 's, the longer the in-breath. \\
\hline hh & An ' $h$ ' indicates an out-breath. The more ' $h$ 's the longer the breath. \\
\hline$(0)$ & A description enclosed in a double bracket indicates a non-verbal activity. For example ((banging sound)) \\
\hline- & A dash indicates the sharp cut-off of the prior word or sound. \\
\hline$:::$ & $\begin{array}{l}\text { Colons indicate that the speaker has stretched the preceding sound or letter. The more colons the greater } \\
\text { the extent of the stretching. }\end{array}$ \\
\hline () & Empty parentheses/brackets indicate the presence of an unclear fragment on the tape. \\
\hline (guess) & The words within a single bracket indicate the transcriber's best guess at an unclear fragment. \\
\hline . & A full stop indicates a stopping fall in tone. It does not necessarily indicate the end of a sentence. \\
\hline Under & Underlined fragments indicate speaker emphasis. \\
\hline$\uparrow \downarrow$ & $\begin{array}{l}\text { Pointed arrows indicate a marked falling or rising intonational shift. They are placed immediately before } \\
\text { the onset of the shift. }\end{array}$ \\
\hline CAPITALS & $\begin{array}{l}\text { With the exception of proper nouns, capital letters indicate a section of speech noticeably louder than } \\
\text { that surrounding it. }\end{array}$ \\
\hline$\circ \circ$ & $\begin{array}{l}\text { Degree signs are used to indicate that the talk they encompass is spoken noticeably quieter than the } \\
\text { surrounding talk. }\end{array}$ \\
\hline Thaght & A 'gh' indicates that word in which it is placed had a guttural pronunciation. \\
\hline$><$ & $\begin{array}{l}\text { 'More than' and 'less than' signs indicate that the talk they encompass was produced noticeably quicker } \\
\text { than the surrounding talk. }\end{array}$ \\
\hline$=$ & The 'equals' sign indicates contiguous utterances. \\
\hline[ & Square brackets between adjacent lines of concurrent speech \\
\hline ] & Indicate the onset (and end) of a spate of overlapping talk. \\
\hline
\end{tabular}

\section{Appendix 2}

Table 2 Descriptions for discourse moves

\begin{tabular}{ll}
\hline Discourse moves & Descriptions \\
TI & The teacher's initiation in the IRF cycle \\
SR & Students' response (more than one student is responding at the same time) in the IRF cycle \\
S1R & The first students responding in the IRF cycle \\
S2R & The second students responding in the IRF cycle \\
S3R & The third students responding in the IRF cycle \\
S4R & The fourth students responding in the IRF cycle \\
S5R & The fifth students responding in the IRF cycle \\
TF & The teacher's feedback in the IRF cycle \\
\hline
\end{tabular}




\section{Appendix 3}

Table 3 List of Abbreviations

\begin{tabular}{ll}
\hline Abbreviations & Full Name \\
\hline the IRF cycle & The Initiation-Response-Feedback cycle \\
L1 & The first language \\
EFL & English as a foreign language \\
L2 & The second language \\
\hline
\end{tabular}

\section{Acknowledgements}

I would like to thank my parents who support me emotionally and financially throughout the whole process. I would like to thank my supervisors, Sue Ollerhead and Michael Michell for their guidance, suggestions, feedback on the study. This study would also have been not possible without the two tutors and their classes, who let me observe their own classes and provide me the essential data for the study.

\section{Funding}

This study is not funded by any organizations.

\section{Availability of data and materials}

The data will not be shared in that the data includes video recordings about young adults. They are sensible with their images being public.

\section{Authors' contributions}

This study was carried out by a single author. The author designed the study, reviewed the literature, collected and analyzed the data and wrote the drafts.

\section{Author's information}

I am a PhD candidate studying language and literacy education in School of Education, University of New South Wales, Australia. I hold a Teaching English to Speakers of Other Language (TESOL) Master's Degree from University of Glasgow (UK). I am interested in bilingual and multicultural education under the influence of sociocultural perspectives and EFL classroom teaching. I am currently doing a research project of a comparative study on the IRF cycle and classroom interactions in EFL classrooms in China and Australia.

\section{Competing interests}

The author declares that he/she has no competing interests.

\section{Publisher's Note}

Springer Nature remains neutral with regard to jurisdictional claims in published maps and institutional affiliations.

Received: 11 September 2017 Accepted: 12 December 2017

Published online: 03 January 2018

\section{References}

Antón, M., \& DiCamilla, F. (1998). Socio-cognitive functions of L1 collaborative interaction in the L2 classroom. Canadian modern language review, 54(3), 314-342.

Atkinson, J. M., \& Heritage, J. (1984). Structures of Social Action. Cambridge University Press.

Auer, P. (1998). Introduction: Bilingual conversation revisited. In P. Auer (Ed.), Code-switching in conversation: Language, interaction and identity (pp. 1-24). London: Routledge.

Baker, C. (1996). Foundations of bilingual education and bilingualism (Vol. 1, 3rd ed.). Bristol: Multilingual Matters.

Blackledge, A., \& Creese, A. (2010). Multilingualism: A critical perspective. London: Continuum.

Butler, Y. G., \& Hakuta, K. (2004). Bilingualism and second language acquisition. In T. K. Bhatia \& W. C. Ritchie (Eds.), The handbook of bilingualism (pp. 114-144). Malden: Blackwell.

Cohen, A. D. (2011). Strategies in learning and using a second language (2nd ed.). Harlow: Longman.

Cook, V. (2001). Using the first language in the classroom. Canadian modern language review, 57(3), 402-423.

Cook, V. (2002). Language teaching methodology and the L2 user perspective, Vivian cook. Portraits of the L2 user, 1, 325.

Cummins, J. (1979). Linguistic interdependence and the educational development of bilingual children. Review of Educational Research, 49(2), 222-251.

Cummins, J. (2005). A proposal for action: Strategies for recognizing heritage language competence as a learning resource within the mainstream classroom. Modern Language Journal, 89(4), 585-592.

Cummins, J. (2008). Teaching for transfer: Challenging the two solitudes assumption in bilingual education. In N. H. Hornberger (Ed.), Encyclopedia of Language and Education. Boston, MA: Spinger US. 1528-1538

Edstrom, A. (2009). Teacher reflection as a strategy for evaluating L1/L2 use in the classroom. Babylonia, 1(09), 12-15.

Franklin, C. E. (1990). Teaching in the target language: Problems and prospects. Language Learning Journal, 2(1), 20-24. 
Gibbons, P. (2006). Bridging discourses in the ESL classroom: Students. Teachers and Researchers: Bloomsbury Academic. Gibbons, P. (2014). Scaffolding Language, Scaffolding Learning: Teaching English Language Learners in the Mainstream Classroom. Heinemann.

Hall, G., \& Cook, G. (2012). Own-language use in language teaching and learning. Language Teaching, 45(3), 271-308. Hall, G., \& Cook, G. (2013). Own-language use in ELT: Exploring global practices and attitudes. London: British Council. Halliwell, S., \& Jones, B. (1991). On target: Teaching in the target language. Pathfinder 5. A ClLT series for language teachers. ERIC. Harbord, J. (1992). The use of the mother tongue in the classroom. ELT Journal, 46(4), 350-355.

Heller, M. (2006). Linquistic minorities and modernity: A sociolinguistic ethnography. London: A\&C Black.

Hellermann, J. (2003). The interactive work of prosody in the IRF exchange: Teacher repetition in feedback moves. Language in Society, 32(1), 79-104.

Howatt, A. P. R. (1984). A history of English language teaching. Oxford: Oxford University Press.

Hutchby, I., \& Wooffitt, R. (2008). Conversation analysis. Cambridge: Polity Press.

Jefferson, G. (2004). Glossary of transcript symbols with an introduction. Pragmatics and Beyond New Series, 125, 13-34. Kim, S. H. O., \& Elder, C. (2005). Language choices and pedagogic functions in the foreign language classroom: A crosslinguistic functional analysis of teacher talk. Language Teaching Research, 9(4), 355-380.

Laviosa, S. (2014). Translation and language education: Pedagogic approaches explored. New York: Routledge.

Littlewood, W., \& Yu, B. (2011). First language and target language in the foreign language classroom. Language Teaching, 44(1), 64-77.

Liu, J. (2007). English language teaching in China : New approaches, perspectives and standards. London; New York: Continuum. Macaro, E. (1997). Target language, collaborative learning and autonomy (Vol. 5): Multilingual matters.

Macaro, E. (2005). Codeswitching in the L2 classroom: A communication and learning strategy. Non-native language teachers, 63-84.

Macdonald, C. (1994). Using the target language. Cheltenham: Mary Glasgow.

Mercer, N., \& Dawes, L. (2014). The study of talk between teachers and students, from the 1970s until the 2010s. Oxford Review of Education, 40(4), 430-445.

Mitchell, R. (1988). Communicative language teaching in practice. London: ERIC.

Newson, D. (1998). Translation and foreign language learning. In K. Malmkjær (Ed.), Translation \& language teaching: lanquage teaching \& translation. University of Michigan: Saint Jerome Publications.

Pablo, I. M., Lengeling, M. M., Zenil, B. R., Crawford, T., \& Goodwin, D. (2011). Students and Teachers' reasons for using the first language within the foreign language classroom (French and English) in Central Mexico. Profile, 13(2), 113.

Philip, K. (2016). Questioning 'English-only' classrooms. In G. Hall (Ed.), The Routledge handbook of English language teaching (pp. 513-526). London: Routledge.

Polio, C. G., \& Duff, P. A. (1994). Teachers, language use in university foreign language classrooms: A qualitative analysis of English and target language alternation. The Modern Language Journal, 78(3), 313-326. doi: https://doi.org/10.2307/330110.

Poole, D. (1990). Contextualizing IRE in an eighth-grade quiz review. Linguistics and Education, 2(3), 185-211 doi: 10 1016/50898-5898(05)80019-1.

Scrivener, J. (1994). Learning teaching: A guidebook for English language teachers (1st ed.). Oxford: Macmillan.

Seedhouse, P. (2004). The interactional architecture of the language classroom: A conversation analysis perspective. MA: Blackwell.

Seedhouse, P. (2007). On ethnomethodological CA and 'linguistic CA': A reply to Hall. The Modern Language Journal, 91(4), 527-533.

Sinclair, J. M. H., \& Coulthard, M. (1975). Towards an analysis of discourse: The English used by teachers and pupils. Oxford: Oxford University Press.

Stanley, P. (2013). A critical ethnography of'Westerners' teaching English in China: Shanghaied in shanghai. Routledge.

Stern, H. H., Allen, J. P. B., \& Harley, B. (1992). Issues and options in language teaching. Oxford: Oxford University Press.

Swain, M., \& Lapkin, S. (2000). Task-based second language learning: The uses of the first language. Language Teaching Research, 4(3), 251-274.

Üstünel, E., \& Seedhouse, P. (2005). Why that, in that language, right now? Code-switching and pedagogical focus. International Journal of Applied Linguistics, 15(3), 302-325.

Verhoeven, L. (1991). Acquisition of biliteracy. Aila review, 8, 61-74.

Vygotsky, L. S., \& Cole, M. (1978). Mind in society: Development of higher psychological processes. Harvard University Press. Waring, H. Z. (2009). Moving out of IRF (initiation-response-feedback): A single case analysis. Language Learning, 59(4), 796-824.

Wei, L., \& Wu, C.-J. (2009). Polite Chinese children revisited: Creativity and the use of codeswitching in the Chinese complementary school classroom. International Journal of Bilingual Education and Bilingualism, 12(2), 193-211.

Wells, G. (1993). Reevaluating the IRF sequence: A proposal for the articulation of theories of activity and discourse for the analysis of teaching and learning in the classroom. Linguistics and Education, 5(1), 1-37 doi: 10.1016/S08985898(05)80001-4.

Zheng, X. M., \& Davison, C. (2008). Changing pedagogy: Analysing ELT teachers in China. London: Continuum. 